Article

\title{
Evaluation of Strip Meniscometry and Association with Clinical and Demographic Variables in a Community Eye Study (in Bangladesh)
}

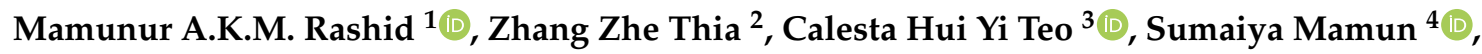 \\ Hon Shing Ong ${ }^{3,5,6}$ and Louis Tong $2,3,5,6, * \mathbb{D}$ \\ 1 Ophthalmology, Cornea unit, Al Noor Eye Hospital, 1/9 E, Satmasjid Road, Lalmatia, Dhaka 1207, \\ Bangladesh; mamun3312@gmail.com \\ 2 Yong Loo Lin School of Medicine, National University of Singapore, 10 Medical Drive, Singapore 117597, \\ Singapore; thiazz1995@hotmail.com \\ 3 Ocular Surface Research Group, Singapore Eye Research Institute, The Academia, 20 College Road, \\ Discovery Tower Level 6, Singapore 169856, Singapore; teohuiyicalesta@gmail.com (C.H.Y.T.); \\ honshing@gmail.com (H.S.O.) \\ 4 Nutrition and Epidemiology, Institute of Nutrition \& Food Science, University of Dhaka, Dhaka 1000, \\ Bangladesh; sumaiya.mamun@du.ac.bd \\ 5 Corneal and External Eye Disease, Singapore National Eye Centre, 11 Third Hospital Ave, \\ Singapore 168751, Singapore \\ 6 Eye-Academic Clinical Program, Duke-NUS Medical School, 8 College Rd, Singapore 169857, Singapore \\ * Correspondence: louis.tong.h.t@singhealth.com.sg; Tel.: +65-6227-7255; Fax: +65-6225-2568
}

Received: 26 August 2020; Accepted: 14 October 2020; Published: 20 October 2020

\begin{abstract}
Strip meniscometry (SM) is a relatively new technique for evaluating inferior tear meniscus. We described SM in an epidemiology study and its potential associations with clinical and tear parameters. This cross-sectional study involved 1050 factory garment workers in Gazipur, Bangladesh. The Ocular Surface Disease Index (OSDI) questionnaire and a standard examination for dry eye and meibomian gland dysfunction (MGD), including the five-second SM, were performed by a single ophthalmologist. The participants' ages were $35.56 \pm 12.12$ years (range 18-59), with $53.8 \%$ women. The overall SM was $7.7 \pm 3.6 \mathrm{~mm}$, with skewness of 0.126 and kurtosis of 1.84 in frequency distribution. $\mathrm{SM}$ values were significantly lower in men than women, and significantly correlated with schirmers $(\mathrm{r}=0.71)$ and tear break up time (TBUT) $(\mathrm{r}=0.89)$. A lower SM value was associated with higher OSDI, lower Schirmer test, increased MG severity and lower TBUT. In multivariable analysis, when adjusted by age, SM values remained associated with schirmers and TBUT, and inversely associated with OSDI. In a separate regression model, higher SM was associated with increasing age, reduced severity of MGD grading, and increased TBUT. To conclude, SM is a rapid clinical test associated with dry eye symptoms and signs, with findings affected by both tear secretion and tear stability.
\end{abstract}

Keywords: dry eye disease; meibomian gland dysfunction; ocular surface disease; dry eye symptoms; questionnaire; Bangladesh; global health; epidemiology

\section{Introduction}

Dry Eye Disease (DED), a multifactorial disease of the ocular surface and loss of homeostasis of the tear film, is associated with visual disturbance, symptoms of ocular discomfort, and tear instability [1-3]. Tear film and Ocular Surface Society Dry Eye Workshop (TFOS DEWS) II reported that this disease affects about $5-50 \%$ of the population. The large variation is due to a large number of research studies on small geographically homogeneous populations. The epidemiology sub-committee 
emphasized the need to expand prevalence studies to more geographical regions, and to include different races and ethnicities [4]. Dry eye can have a significant impact in patients' visual function and quality of life, adversely hindering the ability to carry out daily activities, such as reading or driving. This disease of the ocular surface has thus been an increasing public health concern and it poses significant socioeconomic implications [5-9].

Blepharitis and meibomian gland dysfunction (MGD) are major associated factors of DED. MGD is characterized by chronic abnormalities of the meibomian glands, resulting in altered meibum delivery to the tear film, which can result in poor tear film stability or poor breakup times, a type of dry eye classified as evaporative dry eye. On the other hand, dry eye may also be due to aqueous tear deficiency $[10,11]$.

There is scarce data on the epidemiology of dry eye in developing countries within Asia. In developing countries, dry eye has received minimal clinical management and investigative attention compared to other eye diseases. The healthcare burden of dry eye in such countries is essentially unknown [12]. In Indonesia, the age adjusted prevalence of dry eye symptoms is $27.5 \%$ (95\% CI: 24.8-32.2) [13]. In this report current smoking and pterygium were independent risk factors for the DED [13].

Bangladesh is a country in South Asia located between India and Myanmar, occupying an area of 57,000 square miles, the 8 th most populous country in the world. The per capita GDP of Bangladesh is 4992 USD; the country is considered a low income but has the fastest growing real GDP country in the world. As Bangladesh is a populous country of 163 mil, a properly designed epidemiological study will elicit risk factors and knowledge on dry eye that may not be possible in smaller studies elsewhere.

Among the eye diseases in the urban slums of Dhaka, Bangladesh, ocular surface disease forms an important component. A population-based study in Bangladesh found a prevalence of $17.1 \%$ for conjunctivitis, $1.4 \%$ for blepharitis, $3.2 \%$ for DED, and 3.0\% for pterygium. This study had limitations in its methodologies of ocular surface diseases assessment. For example, slit-lamp examination was only used in the study for diagnoses and symptoms were not quantified [14]. However, we believe that the reported figures are also underestimated, because the prevalence rates of conditions like dry eye and blepharitis are known to be higher when clinical symptoms are included [14].

Previous studies have shown that strip meniscometry is a rapid clinical test (five seconds per eye) for the assessment of lower meniscal tear volume and may be useful for screening. Unlike tests like Schirmer's I, it does not induce reflex tearing $[15,16]$. The results of this test have not been reported in a community setting.

In this study, we performed a community-based study of strip meniscometry in a group of garment factory workers in Bangladesh [17], and potential associations with demographic factors and other clinical factors related to tear function.

\section{Experimental Section}

\subsection{Study Design}

This was a cross-sectional study conducted in a single garment factory in the town of Gazipur, Bangladesh. Participants had given informed verbal consent. The study obtained approval from the local institutional review board (Bangladesh Medical Research Council BMRC/NREC/2017-2018/1157, approved on 2 August 2018), and only utilized clinically accepted procedures and complied with the Tenets of Declaration of Helsinki for human research.

\subsection{Participants}

All participants underwent the following clinical procedures on the initial referral visit. 


\subsection{Study Procedures}

\subsubsection{Questionnaire}

All participants underwent a symptom evaluation using the Ocular Surface Disease Index (OSDI)@ questionnaire (Allergan, Inc., Irvine, CA, USA). Briefly, the OSDI questionnaire consisted of 12 questions, each question graded from 0 to 4 . The total OSDI scores on the scale of 0 to 100 were then calculated with the OSDIC (Allergan, Inc., Irvine, CA, USA) formula (sum of scores) $\times 25 /(12$ questions), with higher scores representing greater symptoms severity [18].

\subsubsection{Strip Meniscometry}

Strip Meniscometry (SM) Tube (Echo Electricity Co., Ltd., Fukusima, Japan) has been performed as in previous studies $[15,16]$. Briefly, one end of the strip was held by the investigator against the lower tear meniscus for five seconds, and the length of wetting of the thread read directly from the millimeter markings provided.

\subsubsection{Fluorescein Breakup Time (TBUT)}

Briefly, a minimally wet (saline) fluorescein strip (Fluorets, Bausch and Lomb, Rochester, NY, USA) was used to instill fluorescein dye. The procedure for this step has been previously described $[19,20]$.

\subsubsection{Schirmer's I Test}

The Schirmer's I test was done with standard $5 \mathrm{~mm}$ wide test strips (Clement Clark ${ }^{\circledR}$, Essex, UK) with a notch for folding, and without prior anesthesia. The strips were positioned over the inferior temporal half of the lower lid margin in both eyes, and participants' eyes subsequently closed. After $5 \mathrm{~min}$, the extent of tear wetting of the strip was measured to the nearest $\mathrm{mm}$ using a ruler [19].

\subsubsection{Meibomian Gland Dysfunction Examination}

The characteristics of the meibum secreted was evaluated by one ophthalmologist using the right thumb with gentle pressure, under slit-lamp microscopy and graded as follows: 0: clear meibum, 1: colored meibum with normal consistency, 2: viscous meibum, 3: inspissated meibum, and 4: blocked meibomian gland. This was used as a measure of MGD severity.

\subsubsection{Slit-Lamp Examination}

Other clinical features were examined using a slit lamp biomicroscope. This included scurfing/crusting, subtarsal papillary reaction $[19,21]$, and regularity of the eyelid margin [22]. Corneal sensitivity was also screened using a cotton wisp [23].

\subsection{Statistical Analysis}

Statistical analysis was performed using StataCorp. 2013. Stata Statistical Software: Release 13.1. College Station, TX: StataCorp LP.

The SM variable was evaluated for its frequency distribution and normality. The univariate association of SM with continuous variables was evaluated by categorizing these variables into binary categories, and the association evaluated with the T-test. Whenever there were more than two categories, analysis of variance was used to determine the statistical significance. Univariate logistic regression was performed between meniscometry category and sex, age, ethnicity, and the six ocular surface signs (tear break up time (TBUT), fluorescein corneal staining, Schirmer's I test, NLMEG, presence of scurf, and inferior fornix papillary grade).

Multivariate logistic regression was performed with meniscometry category as the dependent variable. We performed models using only the clinical signs and demographics of patients, as well as models introducing the predisposing factors of dry eye such as concomitant drugs and 
medical conditions. We performed logistic regressions with two thresholds for SM as the dependent variable. Statistical significance was based on alpha of 0.05 .

\section{Results}

\subsection{Clinical and Characteistics of Participants}

In this study, mean age of participants was $35.56 \pm 12.12$ years (range 18 to 59 ). $53.8 \%$ were women. $64.2 \%$ (95\%CI: 61.2-67.1) of participants had dry eye defined as OSDI $>12$.

\subsection{Distribution of Strip Meniscometry Readings}

The distribution is bimodal and not normal (Figure 1). The mean readings were $7.7 \pm 3.6$.

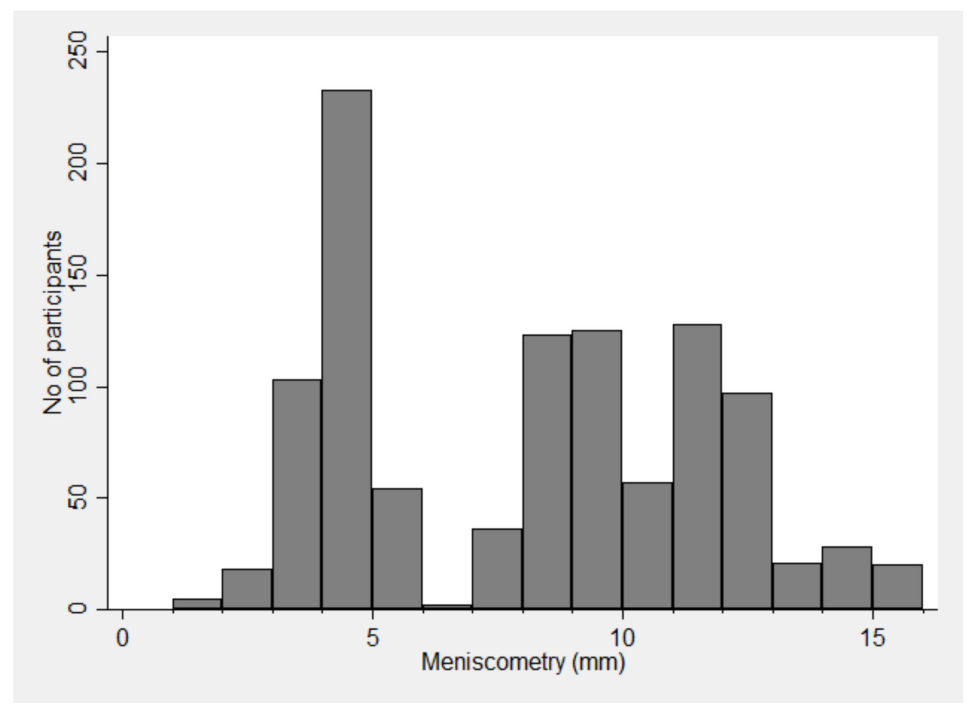

Figure 1. Histogram of strip meniscometry values in factory workers.

\subsection{Factors Affecting Strip Meniscometry}

The factors associated with SM are shown in (Table 1). When performing a T-test to determine the association between MGD and SM, the three grades of MGD were categorized into two categories for the T-test. The smallest two grades of MGD (MGD Types 0 and 1) are combined into one category, whereas MGD Type 2 was used as the other category.

Table 1. Summary of strip meniscometry readings in this study.

\begin{tabular}{|c|c|c|c|}
\hline & $\begin{array}{c}\text { Participants } \\
\text { N (\%) }\end{array}$ & $\begin{array}{c}\text { Strip Meniscometry Reading } \\
\text { Mean } \pm \text { Standard Deviation (SD) } \\
\text { Median (Min, Max) }\end{array}$ & $p$ Value \\
\hline Overall & $\begin{array}{c}1050 \\
(100 \%)\end{array}$ & $\begin{array}{c}7.7 \pm 3.6 \\
8(1,16)\end{array}$ & - \\
\hline \multicolumn{4}{|l|}{ Gender } \\
\hline Female & $\begin{array}{c}485 \\
(46.19 \%) \\
565 \\
(53.81 \%)\end{array}$ & $\begin{array}{l}7.1 \pm 3.8 \\
7(1,16) \\
8.1 \pm 3.3 \\
9(2,16)\end{array}$ & $<0.001$ \\
\hline \multicolumn{4}{|l|}{ Age } \\
\hline$<30$ years & $\begin{array}{c}371 \\
(35.33 \%)\end{array}$ & $\begin{array}{c}8.4 \pm 3.8 \\
10(2,16)\end{array}$ & $<0.001$ \\
\hline 30-40 years & $\begin{array}{c}219 \\
(20.86 \%)\end{array}$ & $\begin{array}{l}7.3 \pm 3.1 \\
8(1,16)\end{array}$ & \\
\hline $40-50$ years & $\begin{array}{c}347 \\
(33.05 \%)\end{array}$ & $\begin{array}{l}6.9 \pm 3.4 \\
8(2,16)\end{array}$ & \\
\hline$>50$ years & $\begin{array}{c}113 \\
(10.76 \%)\end{array}$ & $\begin{array}{l}8.1 \pm 3.6 \\
9(2,14)\end{array}$ & \\
\hline
\end{tabular}


Table 1. Cont.

\begin{tabular}{|c|c|c|c|}
\hline & $\begin{array}{l}\text { Participants } \\
\quad \text { N (\%) }\end{array}$ & $\begin{array}{c}\text { Strip Meniscometry Reading } \\
\text { Mean } \pm \text { Standard Deviation (SD) } \\
\text { Median (Min, Max) }\end{array}$ & $p$ Value \\
\hline \multicolumn{4}{|c|}{ Ocular Surface Disease Index (OSDI) } \\
\hline Low $(<33)$ & $\begin{array}{c}679 \\
(64.67 \%)\end{array}$ & $\begin{array}{l}9.7 \pm 2.5 \\
10(3,16)\end{array}$ & \multirow[t]{2}{*}{$<0.001$} \\
\hline High $(\geq 33)$ & $\begin{array}{c}371 \\
(35.33 \%)\end{array}$ & $\begin{array}{c}3.9 \pm 1.4 \\
4(1,14)\end{array}$ & \\
\hline \multicolumn{4}{|l|}{ Schirmer I test } \\
\hline Low $(<5 \mathrm{~mm})$ & $\begin{array}{c}413 \\
(39.33 \%)\end{array}$ & $\begin{array}{c}4.0 \pm 1.7 \\
4(1,14)\end{array}$ & \multirow[t]{2}{*}{$<0.001$} \\
\hline $\operatorname{High}(\geq 5 \mathrm{~mm})$ & $\begin{array}{c}637 \\
(60.67 \%)\end{array}$ & $\begin{array}{l}10.0 \pm 2.3 \\
10(2,16)\end{array}$ & \\
\hline \multicolumn{4}{|c|}{ Tear Breakup Time (TBUT) } \\
\hline Low $(<5 \mathrm{~s})$ & $\begin{array}{c}369 \\
(35.14 \%)\end{array}$ & $\begin{array}{c}3.8 \pm 1.3 \\
4(1,14)\end{array}$ & \multirow[t]{2}{*}{$<0.001$} \\
\hline High ( $\geq 5 \mathrm{~s})$ & $\begin{array}{c}681 \\
(64.86 \%)\end{array}$ & $\begin{array}{c}9.8 \pm 2.5 \\
10(3,16)\end{array}$ & \\
\hline \multicolumn{4}{|c|}{ Meibomian Gland Dysfunction (MGD) Types } \\
\hline Type 0 & $\begin{array}{c}275 \\
(26.19 \%)\end{array}$ & $\begin{array}{l}11.2 \pm 2.3 \\
11(3,16)\end{array}$ & \multirow[t]{3}{*}{$<0.001$} \\
\hline Type 1 & $\begin{array}{c}182 \\
(17.33 \%)\end{array}$ & $\begin{array}{l}9.8 \pm 2.2 \\
10(4,16)\end{array}$ & \\
\hline Type 2 & $\begin{array}{c}593 \\
(56.48 \%)\end{array}$ & $\begin{array}{c}5.3 \pm 2.4 \\
4(1,14)\end{array}$ & \\
\hline
\end{tabular}

Reduced SM readings were associated with increased OSDI (Figure 2A) $(\mathrm{r}=-0.72, p<0.001)$, directly correlated with Schirmer (Figure 2B) $(\mathrm{r}=0.71, p<0.001)$, and associated with increased MG severity (Figure 2C) $(p<0.001)$.
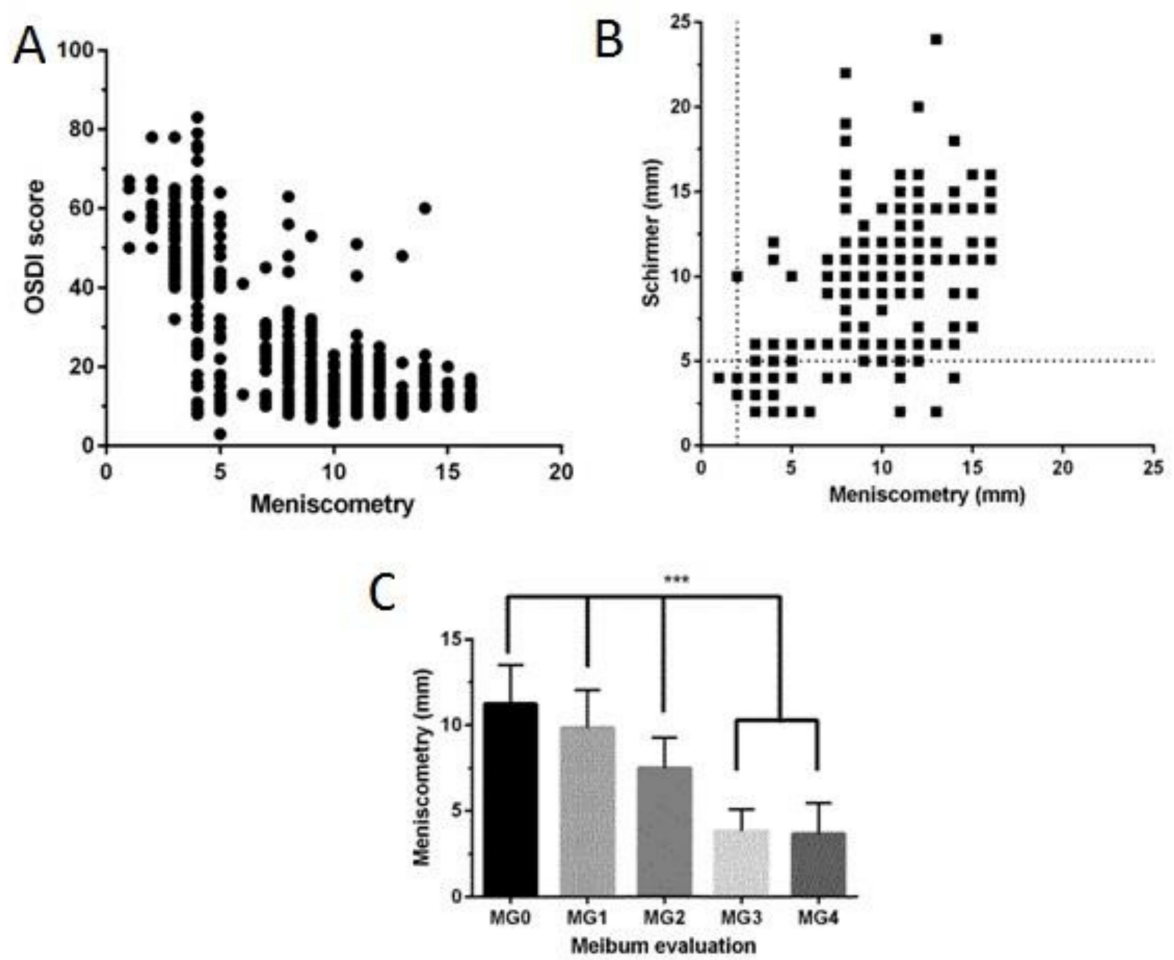

Figure 2. Scatter diagrams showing the relationship between meniscometry and (A) Ocular Surface Disease Index (OSDI) scores, (B) Schirmer test results. (C) Bar graph showing the relationship between meniscometry and meibomian gland dysfunction. MG0: clear meibum, MG1: colored meibum with normal consistency, MG2: viscous meibum, MG3: inspissated meibum, and MG4: blocked meibomian gland. ${ }^{* * *}$ : two-tailed p-value for ANOVA and post-hoc tests, $p<0.001$. 
Interestingly, all the 23 subjects with $\mathrm{SM}<3 \mathrm{~mm}$ had severe dry eye symptoms (OSDI of 33 or more) ( $p<0.001$ on Fischer's exact probability test).

\subsection{Multivariate Analysis}

We first performed logistic regression with SM categorized as $<7 \mathrm{~mm}$ to be low (abnormal), since the mean SM of this study was $7.7 \mathrm{~mm}$. With age, gender, and the clinical parameters as independent variables, we found low values of SM to be significantly associated with higher OSDI and lower Schirmer's readings (Table 2).

Table 2. Multiple logistic regression where dependent variable is the abnormal meniscometry values $(<7 \mathrm{~mm})$

\begin{tabular}{ccccc}
\hline & Model 1 & Model 2 $^{\dagger}$ & Model 3 $^{++}$ & Model 4 $^{+++}$ \\
\hline Parameters & $\begin{array}{c}\text { Unadjusted Odds Ratio } \\
(95 \% \text { Confidence Interval) }\end{array}$ & $\begin{array}{c}\text { Adjusted Odds Ratio } \\
(95 \% \text { Confidence Interval) }\end{array}$ & $\begin{array}{c}\text { Adjusted Odds Ratio } \\
(95 \% \text { Confidence Interval) }\end{array}$ & $\begin{array}{c}\text { Adjusted Odds Ratio } \\
(95 \% \text { Confidence Interval) }\end{array}$ \\
\hline Age & $1.01(1.00-1.02)^{*}$ & $1.00(0.99-1.02)$ & $0.97(0.95-0.99)^{*}$ & $0.97(0.94-1.00)$ \\
Gender & $1.85(1.44-2.38)^{*}$ & $1.83(1.42-2.35)^{*}$ & $1.67(1.06-2.63)^{*}$ & $1.09(0.61-1.94)$ \\
OSDI & $1.16(1.15-1.18)^{*}$ & & $1.17(1.15-1.19)^{*}$ & $1.05(1.02-1.08)^{*}$ \\
TBUT & $0.43(0.39-0.47)^{*}$ & & & $0.87(0.72-1.05)$ \\
Schirmers & $0.17(0.13-0.23)^{*}$ & & $0.43(0.35-0.54)^{*}$ \\
MGD & $12.15(8.96-16.48)^{*}$ & & & $1.42(0.79-2.57)$ \\
\hline
\end{tabular}

${ }^{\dagger}$ Adjusted by Age and Gender; ${ }^{\text {t+ }}$ Adjusted by Age, Gender and OSDI; ${ }^{+++}$Adjusted by Age, Gender, ocular surface disease index (OSDI), tear breakup time (TBUT), Schirmers, and meibomian gland dysfunction (MGD); ${ }^{*}<0.05$.

However, when we performed logistic regression with SM categorized as $<3 \mathrm{~mm}$ to be low (abnormal), we found abnormal SM to be significantly associated with higher OSDI and lower TBUT readings after adjustment for the other variables (Model 4 in Table 3). However there were only 23 or $2.19 \%$ of participants with SM less than $3 \mathrm{~mm}$, so it may or may not be possible to uncover all the associated factors with this sample size.

Table 3. Multiple logistic regression where dependent variable is the abnormal meniscometry values $(<3 \mathrm{~mm})$.

\begin{tabular}{|c|c|c|c|c|}
\hline & Model 1 & Model $2^{+}$ & Model $3^{++}$ & Model $4^{++\dagger}$ \\
\hline Parameters & $\begin{array}{l}\text { Unadjusted Odds Ratio } \\
\text { (95\% Confidence Interval) }\end{array}$ & $\begin{array}{c}\text { Adjusted Odds Ratio } \\
\text { (95\% Confidence Interval) }\end{array}$ & $\begin{array}{c}\text { Adjusted Odds Ratio } \\
\text { (95\% Confidence Interval) }\end{array}$ & $\begin{array}{c}\text { Adjusted Odds Ratio } \\
\text { (95\% Confidence Interval) }\end{array}$ \\
\hline Age & $1.04(1.00-1.08)$ & $1.03(1.00-1.08)$ & $1.02(0.98-1.07)$ & $1.04(0.99-1.09)$ \\
\hline Gender & $2.72(1.11-6.67)$ * & $2.52(1.02-6.19)$ * & $1.84(0.70-4.89)$ & $1.37(0.49-3.82)$ \\
\hline OSDI & $1.13(1.09-1.18)$ * & & $1.13(1.08-1.18)^{*}$ & $1.11(1.06-1.17)^{*}$ \\
\hline TBUT & $0.41(0.29-0.60)$ * & & & $0.48(0.30-0.77)$ * \\
\hline Schirmers & $0.59(0.44-0.78) *$ & & & $1.33(0.94-1.86)$ \\
\hline MGD grading & $4.80(2.63-8.77) *$ & & & $1.67(0.60-4.68)$ \\
\hline
\end{tabular}

\section{Discussion}

The meniscometry readings in this population of garment factory workers in Bangladesh ranged between 1-16 mm, and significantly lower SM readings were found in males, and in participants with higher OSDI, lower TBUT, lower Schirmer's readings, and higher MGD grades.

In the first study performed in a clinic in Japan $(n=90)$, significantly lower SM readings were observed among patients with DED. In addition, the Schirmer's readings, TBUT, mean tear film lipid layer interferometry grade, and vital staining scores were also observed to be lower among patients with DED. With regards to the SM readings, a positive linear correlation exists with the Schirmer's readings as well as the TBUT [16]. In the second study performed in a clinic in Japan $(n=175)$, significantly lower SM readings were observed among patients with DED, with a positive correlation with graticule scale tear meniscus height (TMH) [15]. 
There were no previous studies of SM in a community setting or study based on the Bangladeshi participants.

In our study (Table 2), lower Schirmer and higher OSDI were associated with abnormal meniscometry values after adjusting for the other clinical variables. This is not surprising since Schirmer's I test, apart from a measure of reflex tear secretion, may also be related to the tear volume in the lower meniscus. With a stricter threshold of SM (Table 3), only lower TBUT and higher OSDI were associated with abnormal SM. This may be related to the pre-existing lower meniscal volume to related to tear stability.

This study involved a large sample in the community within a single occupational group. The use of a uniform protocol by a single ophthalmologist provided an accurate and comprehensive analysis and with a higher confidence of estimates. Since the study did not employ a meibomian gland evaluator, the number of meibomian glands yielding liquid meibum was not documented. The number of subjects with SM less than $3 \mathrm{~mm}$ was limited. Another possible limitation is that this study involved only one occupational group. We are not certain why the distribution of SM is bimodal.

\section{Conclusions}

In conclusion, SM is inexpensive, quick and easy to perform, and may be a suitable tool for epidemiology studies. Although associated with dry eye symptoms, this test is not equivalent to any one of the conventional tests, but still related to some aspect of tear function. It should be explored in other populations.

Author Contributions: Data collection, M.A.K.M.R. and S.M.; methodology, M.A.K.M.R., S.M. and L.T.; conceptualization, L.T.; formal analysis, Z.Z.T., C.H.Y.T. and L.T.; writing-original draft preparation, Z.Z.T., C.H.Y.T. and L.T.; writing—review and editing, Z.Z.T., L.T. and H.S.O.; supervision, L.T.; All authors have read and agreed to the published version of the manuscript.

Funding: This research was funded by National Medical Research Council, grant number NMRC \CSA $\mid 017 \backslash 2017$ "

Acknowledgments: Funding advisory board or gifts from Santen, Alcon-Novartis, Allergan, B \& L, LFAsia, Bioessex, Eye-lens, Dyamed, ZAS Ophthalmic, Bangladesh.

Conflicts of Interest: The authors declare no conflict of interest. The funders had no role in the design of the study; in the collection, analyses, or interpretation of data; in the writing of the manuscript, or in the decision to publish the results.

\section{References}

1. Craig, J.P.; Nichols, K.K.; Akpek, E.K.; Caffery, B.; Dua, H.S.; Joo, C.K.; Liu, Z.; Nelson, J.D.; Nichols, J.J.; Tsubota, K.; et al. TFOS DEWS II Definition and Classification Report. Ocul. Surf. 2017, 15, 276-283. [CrossRef]

2. Wolffsohn, J.S.; Arita, R.; Chalmers, R.; Djalilian, A.; Dogru, M.; Dumbleton, K.; Gupta, P.K.; Karpecki, P.; Lazreg, S.; Pult, H.; et al. TFOS DEWS II Diagnostic Methodology report. Ocul. Surf. 2017, 15, 539-574. [CrossRef] [PubMed]

3. Craig, J.P.; Nelson, J.D.; Azar, D.T.; Belmonte, C.; Bron, A.J.; Chauhan, S.K.; de Paiva, C.S.; Gomes, J.A.; Hammitt, K.M.; Jones, L.; et al. TFOS DEWS II Report Executive Summary. Ocul. Surf. 2017, 15, 802-812. [CrossRef]

4. Stapleton, F.; Alves, M.; Bunya, V.Y.; Jalbert, I.; Lekhanont, K.; Malet, F.; Na, K.S.; Schaumberg, D.; Uchino, M.; Vehof, J.; et al. TFOS DEWS II Epidemiology Report. Ocul. Surf. 2017, 15, 334-365. [CrossRef]

5. Clegg, J.P.; Guest, J.F.; Lehman, A.; Smith, A.F. The annual cost of dry eye syndrome in France, Germany, Italy, Spain, Sweden and the United Kingdom among patients managed by ophthalmologists. Ophthalmic Epidemiol. 2006, 13, 263-274. [CrossRef] [PubMed]

6. Wlodarczyk, J.; Fairchild, C. United States cost-effectiveness study of two dry eye ophthalmic lubricants. Ophthalmic Epidemiol. 2009, 16, 22-30. [CrossRef]

7. Sullivan, R.M.; Cermak, J.M.; Papas, A.S.; Dana, M.R.; Sullivan, D.A. Economic and quality of life impact of dry eye symptoms in women with Sjogren's syndrome. Adv. Exp. Med. Biol. 2002, 506, 1183-1188. 
8. Yu, J.; Asche, C.V.; Fairchild, C.J. The economic burden of dry eye disease in the United States: A decision tree analysis. Cornea 2011, 30, 379-387. [CrossRef]

9. Reddy, P.; Grad, O.; Rajagopalan, K. The economic burden of dry eye: A conceptual framework and preliminary assessment. Cornea 2004, 23, 751-761. [CrossRef]

10. Chhadva, P.; Goldhardt, R.; Galor, A. Meibomian Gland Disease: The Role of Gland Dysfunction in Dry Eye Disease. Ophthalmology 2017, 124, S20-S26. [CrossRef] [PubMed]

11. Nichols, K.K.; Foulks, G.N.; Bron, A.J.; Glasgow, B.J.; Dogru, M.; Tsubota, K.; Lemp, M.A.; Sullivan, D.A. The international workshop on meibomian gland dysfunction: Executive summary. Investig. Ophthalmol. Vis. Sci. 2011, 52, 1922-1929. [CrossRef]

12. Osae, A.E.; Gehlsen, U.; Horstmann, J.; Siebelmann, S.; Stern, M.E.; Kumah, D.B.; Steven, P. Epidemiology of dry eye disease in Africa: The sparse information, gaps and opportunities. Ocul. Surf. 2017, 15, 159-168. [CrossRef]

13. Lee, A.J.; Lee, J.; Saw, S.M.; Gazzard, G.; Koh, D.; Widjaja, D.; Tan, D.T. Prevalence and risk factors associated with dry eye symptoms: A population based study in Indonesia. Br. J. Ophthalmol. 2002, 86, 1347-1351. [CrossRef]

14. Sutradhar, I.; Gayen, P.; Hasan, M.; Gupta RDas Roy, T.; Sarker, M. Eye diseases: The neglected health condition among urban slum population of Dhaka, Bangladesh. BMC Ophthalmol. 2019, 19, 38. [CrossRef]

15. Ibrahim, O.M.A.; Dogru, M.; Ward, S.K.; Matsumoto, Y.; Wakamatsu, T.H.; Ishida, K.; Tsuyama, A.; Kojima, T.; Shimazaki, J.; Tsubota, K. The efficacy, sensitivity, and specificity of strip meniscometry in conjunction with tear function tests in the assessment of tear meniscus. Investig. Ophthalmol. Vis. Sci. 2011, 52, 2194-2198. [CrossRef]

16. Dogru, M.; Ishida, K.; Matsumoto, Y.; Goto, E.; Ishioka, M.; Kojima, T.; Goto, T.; Saeki, M.; Tsubota, K. Strip meniscometry: A new and simple method of tear meniscus evaluation. Investig. Ophthalmol. Vis. Sci. 2006, 47, 1895-1901. [CrossRef]

17. Rashid, M.A.K.M.; Teo, C.H.Y.; Mamun, S.; Ong, H.S.; Tong, L. Prevalence and Risk Factors of Severe Dry Eye in Bangladesh-Based Factory Garment Workers. Diagnostics 2020, 10, 634. [CrossRef]

18. Schiffman, R.M.; Christianson, M.D.; Jacobsen, G.; Hirsch, J.D.; Reis, B.L. Reliability and validity of the Ocular Surface Disease Index. Arch. Ophthalmol. 2000, 118, 615-621. [CrossRef]

19. Foong, A.W.; Saw, S.M.; Loo, J.L.; Shen, S.; Loon, S.C.; Rosman, M.; Aung, T.; Tan, D.T.; Tai, E.S.; Wong, T.Y. Rationale and methodology for a population-based study of eye diseases in Malay people: The Singapore Malay eye study (SiMES). Ophthalmic Epidemiol. 2007, 14, 25-35. [CrossRef]

20. Koh, S.; Watanabe, H.; Hosohata, J.; Hori, Y.; Hibino, S.; Nishida, K.; Maeda, N.; Tano, Y. Diagnosing dry eye using a blue-free barrier filter. Am. J. Ophthalmol. 2003, 136, 513-519. [CrossRef]

21. Peterson, R.C.; Wolffsohn, J.S. Objective grading of the anterior eye. Optom. Vis. Sci. 2009, 86, $273-278$. [CrossRef] [PubMed]

22. Terry, R.L.; Schnider, C.M.; Holden, B.A.; Cornish, R.; Grant, T.; Sweeney, D.; La Hood, D.O.; Back, A.R. CCLRU standards for success of daily and extended wear contact lenses. Optom. Vis. Sci. 1993, 70, 234-243. [CrossRef] [PubMed]

23. Bruce, A.S. Preliminary Examination. Contact Lens Pract. 2018. [CrossRef]

Publisher's Note: MDPI stays neutral with regard to jurisdictional claims in published maps and institutional affiliations.

(C) 2020 by the authors. Licensee MDPI, Basel, Switzerland. This article is an open access article distributed under the terms and conditions of the Creative Commons Attribution (CC BY) license (http://creativecommons.org/licenses/by/4.0/). 